\title{
Dynamic Asset Allocation under Mispricing, Predictability and Portable Alpha ${ }^{1}$
}

\author{
HYOUNG-GOO KANG ${ }^{*}$
}

The existing literature about portfolio management has investigated how to update a portfolio allocation, conditional on the information that possibly predicts asset returns and volatilities. We add several innovations to fill the lacuna of prior research in the contexts of global asset allocation. First, we suggest a simple method of how to rebalance portfolios automatically and dynamically in order to exploit potential market inefficiencies. The existing literature has not developed such a strategy. Out-of-sample tests demonstrate that our strategy dominates both static allocation and dynamic strategies that do not account for possible mispricing. Thus, our strategy can contribute not only to academia, but also to practical portfolio managers who endeavor to beat markets. Second, we elaborate portable alpha strategies using the new dynamic strategy. Once we add an alpha portfolio to existing portfolios, then they perform better in terms of mean and risk. Thus, it makes our alpha portfolio portable, i.e., we can apply the alpha portfolio to any fund and can enhance its performance. Third, our dynamic strategy implies a convenient method to estimate a conditional mean and covariance matrix as functions of predictive information while ensuring positive definiteness of the covariance matrix without consuming much computational power. Such estimation strategy can be useful to practical risk managers and traders who need to control the risks of large target portfolios on a real time basis.

Keywords: Portfolio, Dynamic Asset Allocation, Portable Alpha Portfolio, Mispricing, Mean-Variance Optimization

JEL Classifications: G11, G12

Assistant professor at Hanyang University. Business School, 17 Haengdang-dong, Seongdong-gu, Seoul, Korea; Tel: +82-220-0242; Fax: +82-220-0249; E-mail: hyoungkang@hanyang.ac.kr 


\section{INTRODUCTION}

$\mathrm{T}$

his paper investigates dynamic asset allocation strategies in the event that mispricing exists. This paper exhibits several contributions. Firstly, we introduce an innovative method to discover mispricing and to implement dynamic trading strategies in relation to mispricing. Secondly, we identify the role of alpha, conditioning information and short-selling constraints in portfolio management. In particular, we compare the performances of portfolios conditional to whether we can attach 'alpha' portfolios and whether we can estimate underlying parameters of asset returns 'actively.' We construct the alpha portfolio by multiplying baseline asset returns and signs of estimated alphas element by element, in which the alphas pertain to the baseline assets with consideration to mispricing. Active estimation uses the estimated alphas to derive conditional distribution of portfolio returns and helps improve portfolio performance. For example, one can specify the conditional means and covariance matrices of portfolio returns as functions of estimated alphas, and construct a better portfolio. Thirdly, we invent a convenient method to estimate conditional covariance matrices. It is known to be very difficult to estimate a conditional covariance matrix as a function of state variables and to ensure positive semi-definiteness at all times (Brandt and Santa-Clara 2006). We demonstrate an intuitive strategy to overcome the hurdle.

We design our model upon the basis of Hansen and Richard's (1987) model. We use Hansen and Richard's general representation of asset prices to identify possible mispricing. Recent research papers by Brandt and Santa-Clara (2006) and Bansal, Dahlquist and Harvey (2004) also employ Hansen and Richard's model. Their ideas are very similar to each other. They construct new asset space by multiplying base assets and conditioning information every period. Then, they implement usual mean-variance optimization. Such method produces unconditional dynamic trading strategies and widens the investment opportunity set. Bansal and Harvey (1996) suggests a different idea to identify alpha and to measure portfolio performance. In comparison, our paper clarifies the link between identifying mispricing and improving portfolios.

More specifically, our dynamic strategy is innovatively expanding Brandt and Santa-Clara (2006), Bansal, Dahlquist and Harvey (2004) and Hansen and Richard (1987). The existing literature does not investigate how to exploit potential market inefficiencies in portfolio strategies while dynamically and automatically updating portfolio allocation without requiring the attention of portfolio managers. Thus, our strategy can be an ideal black-box strategy popular among quantitative asset managers. In addition, we link our dynamic allocation strategy with a portable alpha strategy, such that we suggest how to attach an alpha strategy of a portfolio to other portfolios in order to beat markets. Finally, we relate our strategy with econometric strategies to estimate the mean and covariance 
of a portfolio. The econometric strategy is conditional on the predictive variables and GARCH dynamics whereas satisfying positive definiteness of the covariance matrix. We achieve them without requiring much computational power.

The remainder of this paper is as follows. First, we explain the key idea of our model. Second, we outline the methods to implement the idea. Third, we apply our model to the problem of global asset allocation. Fourth, we evaluate allocation strategies based on out-of-sample tests. Fifth, we provide intuition of the results. The final section concludes with suggestions for further research.

\section{IDEA}

Our objective is to find assets of which theoretical and observed prices are different. Once they are found, we can investigate their distributions and construct a better investment opportunity set. Let $\pi(p)$ denote a price of the payoff $p$ in a payoff space P. We define two level sets of $\pi$ such that

$$
\begin{aligned}
& \mathrm{R}=\{p \text { in } \mathrm{P}: \pi(p)=1\} \\
& \mathrm{Z}=\{p \text { in } \mathrm{P}: \pi(p)=0\}
\end{aligned}
$$

The set $\mathrm{R}$ is the collection of all payoffs with unit prices, i.e., the set of all returns. We can transform any pay off $p \in \mathrm{P}$ into $r \in \mathrm{R}$ by normalizing the pay off with current price $\pi(p)$. Thus, we can only analyze $R \subset P$ instead of $\mathrm{P}$ to characterize any pay off. The set $\mathrm{Z}$ consists of all payoffs with zero prices. In particular, the difference between two returns should be in $\mathrm{Z}$ under efficient market. Our strategy is to find return differences that are not in $\mathrm{Z}$ under a theoretical pricing operator and to implement an appropriate asset allocation accordingly.

Suppose $r_{1}$ and $r_{2}$ are two observed returns in the economy, and $z_{0}$ is the difference between them: $z_{0}=r_{1}-r_{2}$. Also, let us denote $\pi_{r}(\cdot)$ as the 'observed' pricing operator of the economy that may contain mispricing. To contrast, $\pi(\cdot)$ is the 'correct' pricing operator that we have somehow identified. Given that $r_{1}, r_{2}$ and $\pi_{r}(\cdot)$ are publicly observable, $\pi_{r}\left(z_{0}\right)=0$ holds tautologically. However, since $\pi_{\mathrm{r}}(\cdot)$ may contain mispricing, the correct price $\pi\left(z_{0}\right)$ may not be zero. Roughly speaking, our objective is to increase position in $z_{0}$ if $\pi\left(z_{0}\right)$ is positive, or to decrease position if it is negative.

\section{IMPLEMENTATION}

We implement our ideas with the procedure described in. The central issue is how to derive the correct pricing operator and to find mispricing. We can 
do it upon the intuition of Hansen and Richard (1987) and conditional information that may predict asset returns. We demonstrate the procedure in the following subsections.

Table 1. Our Strategy and Asset allocation Procedure

\begin{tabular}{|c|c|c|}
\hline Step & Action & Description \\
\hline 1 & $\begin{array}{l}\text { Determine asset } \\
\text { space }\end{array}$ & We choose what kind of assets to allocate. \\
\hline 2 & $\begin{array}{l}\text { Collect predictive } \\
\text { variables }\end{array}$ & $\begin{array}{l}\text { We can collect macro and micro variables that predict the distribution } \\
\text { of future asset returns. Once we collect them, we can do preliminary } \\
\text { analyses such as univariate regression in order to check whether they } \\
\text { indeed have significant predictive power. }\end{array}$ \\
\hline 3 & $\begin{array}{l}\text { Derive theoretical } \\
\text { pricing operator }\end{array}$ & $\begin{array}{l}\text { To find mispricing, we need an asset-pricing model. In particular, } \\
\text { we use the intuition of Hansen and Richard (1987). The } r^{*} \text { and } z^{*} \\
\text { in rheir paper has an important role in our paper. }\end{array}$ \\
\hline 4 & $\begin{array}{l}\text { Identify } \\
\text { mispricing }\end{array}$ & $\begin{array}{l}\text { We find anomalies that contradict the intuition of Hansen and Richard. } \\
\text { The anomalies create extra investment opportunities. We use com- } \\
\text { ponents of pricing operators }\left(r^{*}, z^{*}\right) \text { to identify such anomalies. }\end{array}$ \\
\hline 5 & $\begin{array}{l}\text { Determine } \\
\text { optimal allocation }\end{array}$ & $\begin{array}{l}\text { We perform mean-variance optimization to derive optimal asset } \\
\text { allocation. In particular, conditional information and mispricing should } \\
\text { affect the allocation. }\end{array}$ \\
\hline
\end{tabular}

Suppose there are $\mathrm{K}+1$ returns $r_{0}, \cdots, r_{\mathrm{K}}$ including an augmented asset menu. An augmented asset menu contains the multiplications (Kronecker product) of baseline assets with state variables in addition to the baseline assets. The variables that possibly predict asset returns are natural state variables. We use augmented asset space in order to construct the pricing operator that may be a time varying subject in conditioning information. Pricing operator $\pi(\cdot)$ is defined as $E\left(p^{*} \cdot\right)$. We define $r^{*}=p^{*} / \pi\left(p^{*}\right)$.

Let us define a random $(\mathrm{K}+1)$-column vector $r$ consisting of the returns $\left\{r_{0}, \cdots, r_{K}\right\}$. Given a return $r_{0}$, let us define $z_{i}=r_{i}-r_{0} . z$ denotes a random K-column vector consisting of those $z_{i}$. Then, any return $r_{i}$ can be expressed as follows (Hansen and Richard 1987):

$$
\tilde{r}_{i} \equiv r_{i}-r^{*}=\beta \mathrm{z}^{*}+n_{\mathrm{i}}
$$

We will call $r^{*}$ and $z^{*}$ as benchmark return and benchmark excess return, respectively. $r^{*}$ and $z^{*}$ are derived as follows.

$r^{*}: \mathrm{E}_{\mathrm{t}}\left(r^{*} \cdot r^{*}\right) \leq \mathrm{E}_{\mathrm{t}}(r \cdot r)$ for all return $r$ and $\mathrm{E}_{\mathrm{t}}\left(r^{*} \cdot z\right)=0$ for all zero cost payoff $z$

$z^{*}: \mathrm{E}_{\mathrm{t}}\left(z^{*} \cdot z\right)=\mathrm{E}_{\mathrm{t}}(z)$ for all zero cost pay off $z$ 
For example, we can derive $r^{*}$ and $z^{*}$ with linear projection.

$$
\begin{aligned}
& r^{*}=-\mathrm{E}_{\mathrm{s}}\left(z z^{\prime}\right)^{-1} \mathrm{E}_{\mathrm{c}}\left(z r_{0}\right) r \\
& z^{*}=\mathrm{E}_{\mathrm{t}}\left(z z^{\prime}\right)^{-1} \mathrm{E}_{\mathrm{t}}(z) z
\end{aligned}
$$

$\beta_{1}$ in the Hansen and Richard's decomposition is the linear projection coefficient without constant. Projection error $n_{i}$ are orthogonal to both $r^{*}$ and $z^{*}$. It is important to notice that the conditional distribution of asset returns are time varying. Conditional distributions can be functions of conditional information. Thus, we use an augmented asset menu to define $r^{*}$ and $z^{*}$ which characterize asset returns. Indeed, the augmented asset menu spans the space that accounts for the relationship between asset returns and conditional information. Alternatively, let us consider the following linear equation:

$$
\tilde{\mathbf{r}}_{\mathrm{i}} \equiv \mathrm{r}_{1}-\mathrm{r}^{*}=\mathrm{a}_{\mathrm{i}}+\beta_{1} \mathrm{z}^{*}+\mathrm{n}_{\mathrm{i}}
$$

in which $a_{i}$ and $\beta_{i}$ are the projection coefficients with constant. We can interpret alpha as excess return or temporary mis-valuation that can be present in an augmented asset space. To reiterate, $\tilde{r}_{1}$ and $z^{*}$ are the excess return from a zero cost portfolio. Thus, $a_{i}$ should be zero if a financial market is efficient. This point becomes clearer if we apply the pricing function to each side. In this case, the left hand side is zero, but the right hand side is a. Thus, a should be zero. If not, it means arbitrage opportunities. Let us consider another illustration. Consider $r_{i}-r^{*}=a_{i}+\beta_{i} z^{*}+n_{i}$. Then, an investor will hold $\left(a_{i}, \beta_{i}\right)$ unit of $\left(1, z^{*}\right)$ instead of holding $(1,-1)$ of $\left(r_{i}, r^{*}\right)$ because $n_{i}$ is mean-zero and orthogonal to both $\left(1, z^{*}\right)$. This means that an investor willingly spends $a_{i} /\left(1+r_{f}\right)$ dollar for the zero cost portfolio. It implies that the price of the zero cost portfolios is not zero, which results in discrepancy between observed and theoretical pricing. We now look at cases that violate Hansen and Richard conditions. If a case ever violates conditions, it creates a trading opportunity.

\section{APPLICATION: GLOBAL ASSET ALLOCATION}

In this section, we illustrate our idea with a practical application given the steps of implementation outlined in.

\section{Determining the Type of Assets in Allocation}

Let us consider a global asset allocation problem. We contemplate the choice between US stocks/bonds and European stocks/bonds and a risk-free asset as in Table 2. As a proxy for the returns from US stock investment, we used 
the S\&P 500 index. The two-year US Treasury note stands for investment in the US bond market. To construct the proxy for the investment in the European stock market, we collected stock market indexes of the UK, France and Germany and weighted them equally. Similarly, we equally weighted two-year government bond returns of the aforementioned countries to approximate the investment returns in the European bond market. Finally, to proxy the returns from risk free asset, we used $4.04 \%$, the annualized average of US federal fund rates for 400 weeks $(9 / 30 / 1994 \sim 6 / 24 / 2005)$. Our results remained robust when we used LIBOR instead of the fixed rate.

\section{Table 2. Global. Portfolio}

\begin{tabular}{c|l}
\hline Asset class & \multicolumn{1}{|c}{ Approximation } \\
\hline US stock & S\&P S00 index \\
\hline US bond & Two year US treasury note \\
\hline Euro stock & Equally weighted average of FTSE 100, CAC 40 and DAX \\
\hline Euro bond & $\begin{array}{l}\text { Equally weighted average of two-year UK, French and German government } \\
\text { bonds }\end{array}$ \\
\hline Risk free asset & Average federal fund rate $(4.04 \%)$ \\
\hline NOTES: We consider global asset allocation composed of five asset classes consisting of US stocks/bonds, \\
$\begin{array}{c}\text { European stocks/bonds and risk free assets. The first column is the target asset classes, and } \\
\text { the second column is its description. The average federal fund rates are computed with a } \\
\text { sample average between the dates } 1 / 24 / 1992 \sim 6 / 24 / 2005 \text {. }\end{array}$
\end{tabular}

All data were extracted from Bloomberg with weekly frequency. We deliberately chose weekly frequency in order to control weekend effects and non-synchronous trading. We demonstrated our validity at weekly frequency, so that applying our model to trading at daily or higher frequency could be more powerful. In addition, it is important to remember that the cited papers (Brandt and Santa-Clara 2006; Bansal, Dahlquist and Harvey 2004) and many other similar papers do not investigate the trading strategies at a higher frequency than at weekly frequency.

Summary statistics of weekly returns for eight asset classes will be provided upon request. The eight asset classes included stock market indexes and government bond indexes for the United States, the United Kingdom, France and Germany. Stock market indexes were S\&P 500 for the US, FTSE 100 for UK, CAC 40 for France and DAX for Germany. Bond indexes were weekly rates of two-year government bonds.

The weekly log returns on the S\&P 500, FTSE 100, CAC 40 and DAX have been $15 \mathrm{bps}, 10 \mathrm{bps}, 12 \mathrm{bps}$ and $14 \mathrm{bps}$, respectively. Thus, the annual returns were about $7.7 \%, 5.1 \%, 6.2 \%$ and $7.4 \%$, respectively. We computed the returns in view of US investors to take into account currency appreciations. The annualized two-year government bond returns for the US, the UK, France and Germany 
were $6.6 \%, 5.4 \%, 5.0 \%$ and $4.7 \%$ in that order. The weekly standard deviations for the US, the UK, France and German stock market returns were $2.1 \%$, $2.2 \%, 2.7 \%$ and $3.1 \%$. The standard deviations for two-year governments bonds were $1.2 \%, 1.4 \%, 1.5 \%$ and $0.3 \%$. We also reported the correlation between assets. Stock market returns were highly correlated with each other. All correlations were over $50 \%$. The US, UK and French bond returns were also highly correlared with each other, over $65 \%$. However, German bonds moved rather independently.

\section{Collect Predictive Variables}

The information variables that will be used to predict asset distributions are dividend yield (Yield), the Baa-Aaa yield spread (Spread), the difference of a 10-year and a 2-year bond yield (Slope), and the yield on the 2 year bill (Level). We did not use non-US spreads because the time series for suitable European corporate bonds was not adequate in length. The chosen predictive variables are in line with related literature (See Ang and Bakaert 2007). The summary statistics about the information variables will be provided upon request.

Weckly dividend yield was highest in the UK (7 bps) and lowest in the US ( 4 bps). The yield of France and Germany were about 5 bps. The yield curve slope has been highest in Germany ( 1.81 bps) and lowest in the UK $(0.5 \mathrm{bp})$. Slope of the US and France were 1.55 bps and 1.73 bps. Annualized average yields from two year government bills were $5.8 \%$ (US), $5.64 \%$ (UK), $3.98 \%$ (France) and 3.75\% (Germany).

Among the information variables, only the correlations between levels were high. It suggests that the government bonds are substitutes of each other. Correlations between other information variables were fairly low so that we can presume the information variable to represent different information. We also report univariate correlations between information variables and one-period-ahead asset returns in Table 3 . Shaded values are significant at $5 \%$.

In terms of a univariate relation, US levels are predictive of the UK and French stock returns. Thus, if two-year US bond yields have risen, UK and French stock market returns have risen too. US yield are also predictive of German bond returns. If the US dividend-price ratio lowered, German bond returns declined. The UK yield and slope forecasted the UK and French stock returns respectively in opposite directions. Increase in UK yield and slope meant decreased UK and French stock returns respectively. French yield and level also forecasted UK bonds and US stock returns respectively in opposite direction. In conclusion, we can conjecture that there is a relation between asset returns and information variables. To investigate the predictability further, we performed multivariate regression of returns on information variables. Table 4 presents Wald statistics. We tested whether the regression model would be rejected or not. The numbers are shaded if the information variables are jointly significant to explain returns at $5 \%$. If 
Table 3. Univariate Correlation Between Returns and information Variables

\begin{tabular}{|c|c|c|c|c|c|c|c|c|c|}
\hline \multirow{2}{*}{\multicolumn{2}{|c|}{ correlations }} & \multicolumn{4}{|c|}{ Stock } & \multicolumn{4}{|c|}{ Bond } \\
\hline & & \multirow{2}{*}{\begin{tabular}{c|} 
US \\
0.0146
\end{tabular}} & \multirow{2}{*}{\begin{tabular}{|l|} 
UK \\
0.0602
\end{tabular}} & \multirow{2}{*}{\begin{tabular}{|l|} 
FRA \\
0.0655 \\
\end{tabular}} & \multirow{2}{*}{$\frac{\text { GER }}{0.0558}$} & \multirow{2}{*}{$\begin{array}{c}\text { US } \\
-0.0151\end{array}$} & \multirow{2}{*}{$\frac{\text { UK }}{0.0505}$} & \multirow{2}{*}{\begin{tabular}{|l|} 
FRA \\
0.0486
\end{tabular}} & \multirow{2}{*}{$\frac{\text { GER }}{0.0131}$} \\
\hline US & Yield & & & & & & & & \\
\hline & Slope & -0.0252 & 0.0140 & 0.0085 & 0.0281 & 0.0485 & 0.0676 & 0.0730 & -0.1962 \\
\hline & Leve! & 0.0365 & 0.0012 & 0.0048 & $0.017 !$ & -0.0519 & -0.0849 & -0.0834 & 0.0883 \\
\hline & Spread & -0.0735 & -0.0769 & -0.0570 & -0.0831 & -0.0368 & 0.0211 & 0.0259 & 0.0187 \\
\hline \multirow[t]{3}{*}{ UK } & Yield & 0.0129 & -0.0018 & 0.0118 & -0.0325 & -0.0439 & -0.0200 & -0.0327 & -0.0913 \\
\hline & Slope & 0.0210 & 0.0343 & -0.0049 & 0.0348 & 0.0325 & 0.0373 & 0.0348 & -0.0802 \\
\hline & Level & 0.0465 & 0.0210 & 0.0178 & 0.0369 & -0.0080 & -0.0362 & -0.0378 & 0.0896 \\
\hline \multirow[t]{3}{*}{ France } & Yield & 0.0361 & 0.0212 & 0.0152 & 0.0359 & 0.0211 & -0.0012 & -0.0080 & -0.0322 \\
\hline & Slope & 0.0422 & 0.0583 & 0.0741 & 0.1068 & 0.0215 & -0.0543 & -0.0566 & -0.1822 \\
\hline & Level & -0.0021 & -0.0307 & -0.0442 & -0.0220 & -0.0134 & 0.0241 & 0.0286 & 0.1293 \\
\hline \multirow[t]{3}{*}{ German } & Yield & 0.0299 & 0.0196 & -0.0110 & 0.0234 & 0.0197 & -0.0172 & -0.0098 & -0.0220 \\
\hline & Slope & 0.0769 & 0.0884 & 0.0802 & 0.1148 & 0.0125 & -0.310 & -0.0366 & -0.1174 \\
\hline & Level & -0.0255 & -0.0514 & -0.0565 & -0.0338 & -0.0163 & 0.0137 & 0.0193 & 0.1282 \\
\hline
\end{tabular}

NOTES: Weekly frequency, Beginning date: 3/9/1990, Ending date: $6 / 24 / 2005, N=570$. This table presents univariate correlations between one period ahead returns and information variables. Shaded are the significant coefficients at $5 \%$.

they are significant at $10 \%$ they are in bold characters. We computed the values under the null hypothesis that the models contain only a constant term.

We of course tested various predictability regressions for eight asset classes. Information variables used in predictability regressions are at the head of Table 4. For example, the US means information variable of US, US*UK is US and UK information variables with interaction, Slope*Spread is slope and spread information variables. Bond returns are generally more predictable than stock returns. In particular, Level and Slope variables can predict bond returns. They sometimes predict stock returns too if we combine independent variables carefully. Dividend yield are not so useful to predict weekly returns in multivariate linear regression models. In sum, we can confirm the evidence of predictability. Thus, the selected variables are useful to estimate conditional distributions of portfolios and to determine the prices of future payoff. Given that we equally weighted EU stock indexes and EU bond indexes, we also equally weighted information variables of Europe.

\section{Deriving the Theoretical Pricing Operator}

We need to estimate Hansen and Richard benchmark returns $\left(r^{*}\right)$ and benchmark excess returns $\left(z^{*}\right)$. The benchmark returns constitute the theoretical pricing 
TABle 4. Wald Statistics for Predictability Regressions

\begin{tabular}{|c|c|c|c|c|c|c|c|c|c|}
\hline Wald & statitics & US & UK & FR & GE & US*UK & US*FR & US*GE & US*UK*FR*GE \\
\hline \multirow[t]{4}{*}{ Stock } & 1 US & 3.5728000 & 1.3500000 & 1.7808000 & 4.3858000 & 3.6688000 & 4.5571000 & 7.1743000 & 9.4367000 \\
\hline & 2 UK & 4.8953000 & 0.7914000 & 2.5103000 & 6.5429000 & 5.1523000 & 6.2162000 & 8.8321000 & 10.4162000 \\
\hline & 3 FRA & 3.6252000 & 0.3290000 & 3.9773000 & 5.9926000 & 5.5926000 & 7.8667000 & 10.2602000 & 12.7145000 \\
\hline & 4 GER & 4.9285000 & 1.9824000 & 7.3768000 & 8.8547000 & 7.2370000 & 9.0083000 & 10.3007000 & 13.4876000 \\
\hline \multirow[t]{5}{*}{ Bond } & SUS & 3.9644000 & 2.1655000 & 0.5769000 & 0.4639000 & 9.7005000 & 6.5678000 & 7.0953000 & 14.7063000 \\
\hline & $6 \mathrm{UK}$ & 6.1759000 & 2.4634000 & 1.8556000 & 0.8434000 & 14.1842000 & 14.8322000 & 15.3317000 & 17.4412000 \\
\hline & 7 FRA & 6.0804000 & 2.8779000 & 2.1338000 & 1.0741000 & 13.0449000 & 14.9730000 & 15.4220000 & 17.8759000 \\
\hline & 8 GER & 26.3361000 & 14.7792000 & 27.2089000 & 19.1396000 & 42.5748000 & 42.0858000 & 45.6270000 & 53.5569000 \\
\hline & & US slope & US spread & Yiclds & Levels & Slopes & Level*Slope & Level*Sperad & Slope*Spread \\
\hline \multirow[t]{4}{*}{ Stock } & 1 US & 0.3607000 & 3.0900000 & 1.1597000 & 8.4112000 & 5.8719000 & 6.5593000 & 8.5298000 & 5.8738000 \\
\hline & $2 \mathrm{UK}$ & 0.1109000 & 3.3866000 & 2.3942000 & 7.8272000 & 6.0017000 & 7.3457000 & 7.8273000 & 6.0072000 \\
\hline & 3 FRA & 0.0410000 & 1.8576000 & 2.7157000 & 7.2053000 & 8.2568000 & 11.0959000 & 7.4309000 & 8.5646000 \\
\hline & 4 GER & 0.4509000 & 3.9548000 & 3.4577000 & 6.5325000 & 10.2650000 & 12.9544000 & 6.6229000 & 10.4546000 \\
\hline \multirow[t]{4}{*}{ Bond } & 5 US & 1.3414000 & 0.7736000 & 1.5383000 & 6.8290000 & 1.5406000 & 3.5107000 & 7.1289000 & 4.1924000 \\
\hline & $6 \mathrm{UK}$ & 2.6152000 & 0.2523000 & 2.1930000 & 14.6954000 & 8.2634000 & 10.4589000 & 14.6994000 & 9.0513000 \\
\hline & 7 FRA & 3.0501000 & 0.3832000 & 2.4843000 & 14.8773000 & 9.0693000 & 11.7359000 & 14.8780000 & 9.952000 \\
\hline & 8 GER & 22.7813000 & 0.1981000 & 6.1162000 & 10.0893000 & 33.1005000 & 40.1092000 & 10.8584000 & 35.0516000 \\
\hline
\end{tabular}

NOTES: Weekly frequency, Beginning date: 3/9/1990, Ending date: $6 / 24 / 2005, N=570$. We tried various predictability regressions for eight asset classes. Used information variables are at the head of table. For example, US means information variable of US, US*UK is US and UK information variables. Slope* ${ }^{*}$ pread is slope and spread information variables. Shaded area denotes the regression model is significant at $5 \%$, and bold-faced values are at $10 \%$. We use Wald statistics to test model specification. 
operator and equilibrium expected returns. Since asset return distributions are predictable with respect to conditioning variables, it is also natural that $r^{*}$ and $z^{*}$ are subject to the information variables. To account for the predictability, we constructed an augmented asset space with $I_{t}\left(r_{i t}-r_{f}\right) . I_{t}$ includes constant and information variables. Then we compute $r^{*}$ and $z^{*}$ as explained in the previous section. Brandt and Santa-Clara (2006) and Bansal et al. (2004) base theirs on the same idea. The weights are computed with a full set of data. Both $r^{*}$ and $z^{*}$ contain extreme weights such as large long or short positions. However, we do not need to construct portfolios for $r^{*}$ and $z^{*}$ in practice. We use the

TABLE 5. PORTFOLIO WEIGHTS FOR $\mathbf{R}^{*}$

\begin{tabular}{c|c|c|c|c}
\hline \multicolumn{1}{c|}{$\mathrm{r}^{*}$} & US stock & EU stock & EU bond & US bond \\
\hline 1 & -0.03890 & 0.00110 & -0.01630 & -0.196000 \\
\hline us yield & 0.14190 & -0.16250 & 0.29800 & -0.65990 \\
\hline us slope & 0.00420 & 0.00120 & -0.00280 & 0.03960 \\
\hline us level & 0.00600 & -0.00540 & 0.01490 & 0.02010 \\
\hline us spread & 0.03590 & -0.01840 & 0.04150 & 0.17890 \\
\hline eu yield & -0.03300 & 0.01840 & -0.02340 & 0.29600 \\
\hline cu slope & 0.00160 & -0.00500 & 0.00620 & 0.06780 \\
\hline su level & -0.00540 & 0.00960 & -0.02030 & -0.03620 \\
\hline
\end{tabular}

NOTES: Weekly frequency, Beginning date: 3/9/1990, Ending date: $6 / 24 / 2005, N=570$. This table shows the portfolio weights to construct Hansen and Richard benchmark return $r^{*}$ over augmented asset space. The column and row names together denote augmented asset menus. For example, the number 0.00490 at (us slope) $\times$ (US stock) means the portfolio weight on the augmented asset menu us_stock*us_slope is 0.0049 .

TABle 6. PORTFOlio WeIGHTS FOR $Z^{*}$

\begin{tabular}{r|r|r|r|r}
\hline \multicolumn{1}{c|}{$\mathrm{r}^{*}$} & US stock & EU stock & EU bond & US bond \\
\hline I & 51.22 & -1.42 & 21.41 & 257.76 \\
\hline us yield & -186.65 & 213.69 & -391.91 & 867.92 \\
\hline us slope & -5.47 & -1.57 & 3.74 & -52.14 \\
\hline us level & -7.89 & 7.09 & -19.53 & -26.44 \\
\hline us spread & -47.17 & 24.14 & -54.64 & -253.30 \\
\hline eu yield & 43.45 & -24.15 & 30.76 & -389.29 \\
\hline eu slope & -2.12 & 6.59 & -8.14 & -89.15 \\
\hline su level & 7.13 & -12.68 & 26.74 & 47.65 \\
\hline
\end{tabular}

NOTES: Weekly frequency, Beginning date: $3 / 9 / 1990$, Ending date: $6 / 24 / 2005, N=570$. This table shows the portfolio weights to construct Hansen and Richard benchmark excess return $z^{*}$ over augmented asset space. Column and row names together denote augmented asset menus. For example, the number -6.41 at (us slope) $\times$ (US stock) means the portfolio weight on the augmented asset menu us stock*us slope is -6.41 . 
TABle 7. SUmmary Statistics for Hansen AND RiChard Benchmark Returns

\begin{tabular}{c|c|c|c|c|c}
\hline Er* & std(r*) & Er*r* & Ez* & Ez*z* & Er*z* \\
\hline $6.5308 \mathrm{e}-004$ & $2.6485 \mathrm{e}-004$ & $4.9652 \mathrm{e}-007$ & 0.1410 & 0.1410 & $8.1888 \mathrm{e}-020$ \\
\hline
\end{tabular}

NOTES: Weckly frequency, Beginning date: 3/9/1990, Ending date: 6/24/2005, $\mathrm{N}=570$

This table shows sample moments of $r^{*}$ and $z^{*}, r^{*}$ and $z^{*}$ are generated with fixed weights in Table 5 and Table 6 respectively.

portfolios only conceptually in order to estimate other parameters. This point will be explained further in the paper. We find that $\mathrm{Er}^{*} \mathrm{r}^{*}$ is very small as expected because $\mathrm{r}^{*}$ is minimum second moment return, and $\mathrm{Ez} *=\mathrm{Ez}^{*} \mathrm{z}^{*}$ and $\mathrm{Er}^{*} \mathrm{z}^{*}=0$ given the orthogonality condition. Thus, these results confirm that our benchmark returns are well defined.

\section{Identify Mispricing}

We identify mispricing with the following linear asset pricing model.

$$
r_{1, r+1}-r^{*}=a_{i, t+1}+\beta_{i, t+1} z^{*}+n_{i, r+1}
$$

For simplicity, we use the following assumptions to estimate the underlying parameters.

$$
\beta_{t+1}=\beta\left(1_{t}\right)
$$

We assume that next period beta is measurable with respect to the current information set. In particular, we assume linear functional form for $\beta(\cdot)$ to make estimation easier. The correct specification is possibly $\beta_{t+1}=\beta\left(I_{t}\right)+\varepsilon_{\beta, t+1}$ or $\beta(\cdot)$ maybe nonlinear. We ignore the error term although it may cause errors-in-variable bias. We assume the error term small enough to ignore it. Shanken (1990) and Ferson and Harvey (1991, 1994) use the same setup so that betas and alphas are linear functions of macro variables available at current period. We include all information variables to estimate beta.

Suppose investors estimate the functional form of beta at every period. In other words, the investor runs a linear regression model $r_{i, t+1}-r *=a_{i, t+1}+\beta_{i, t+1}$ $z^{*}+n_{i, t+1}$ with data up to time $t$ to estimate alpha and beta of $t+1$. At $t+1$, she runs regression again to estimate parameters of $t+2$. We present time series of such estimated betas during the last 500 weeks.

Estimated betas are positive on average. In addition, the correlation table displays some interesting patterns. The betas of US and EU stocks tend to move together. And the betas of US and EU bonds tend to move together. On the other hand, the betas of US/EU stocks and US/EU bonds move in opposite ways. It possibly suggests that geographic diversification generates less 


\section{Figure 1: Time Series of Alphas}

US stock: $1 / 24 / 1992-6 / 24 / 2005$

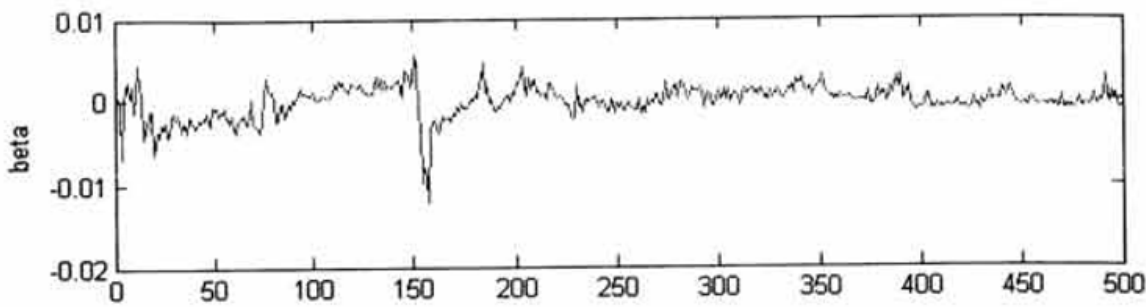

EU stock

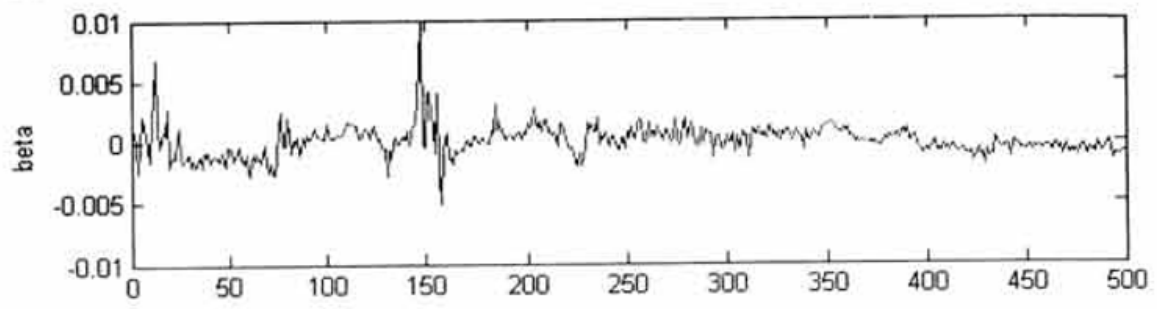

EU bond

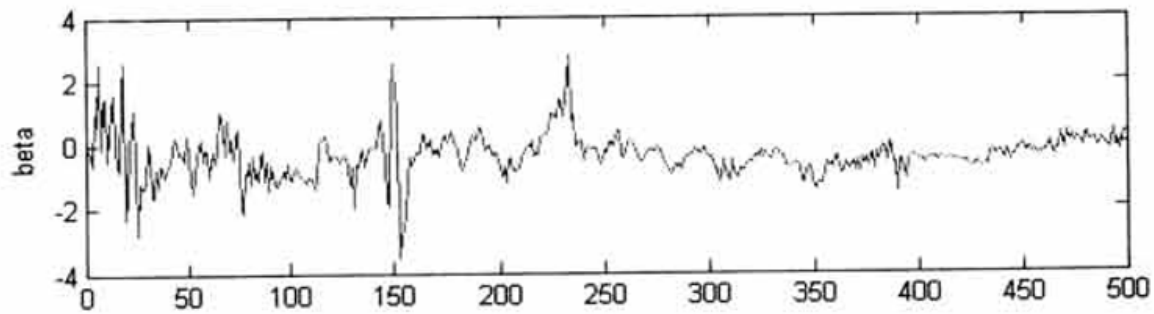

US bond

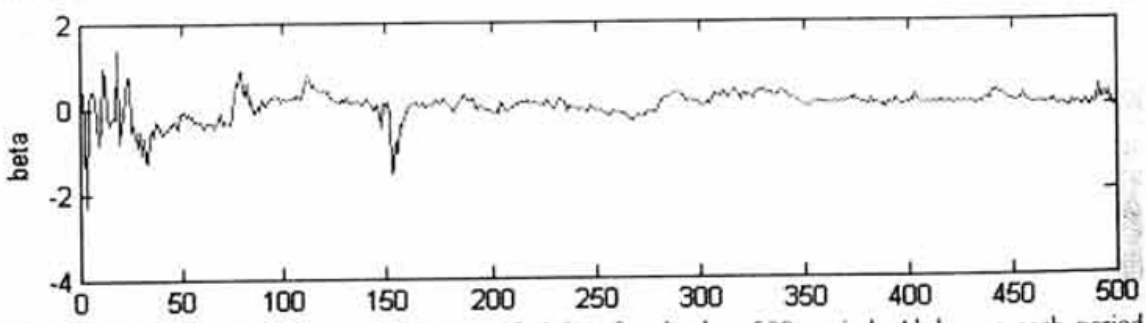

NOTES: This figure shows the time series of alphas for the last 500 period. Alphas at each period are estimated using the history of data up to the moment. The regression model is $\mathrm{r}_{\mathrm{r}} \mathrm{r}^{*}=\mathrm{a}_{\mathrm{a}}+\beta$ $2^{*}+$ ni. And $a$ and 3 are the functions of information variables. Since the regression model is iteratively estimated, the functional form of $a$ and 4 changes at every period too.

benefit than the asset class diversification. For example, a US stock investor should consider US bonds or EU bonds rather than EU stocks to reduce exposure 
TABle 8. SUmmary Statistics OF Alphas

\begin{tabular}{|c|c|c|c|c|c|c|c|c|c|c|c|}
\hline \multirow{2}{*}{\multicolumn{3}{|c|}{ alphas }} & \multirow{2}{*}{ mean } & \multirow{2}{*}{ std } & \multirow{2}{*}{ median } & \multirow{2}{*}{$\min$} & \multirow{2}{*}{$\max$} & \multicolumn{4}{|c|}{ correlation } \\
\hline & & & & & & & & 1 & 2 & 3 & 4 \\
\hline 1 & US : & stock & 0.0000 & 0.0019 & 0.0001 & -0.0122 & 0.0057 & 1.0000 & & & \\
\hline 2 & EU : & stock & 0.0000 & 0.0012 & 0.0000 & .0 .0051 & 0.0099 & 0.6137 & 1.0000 & & \\
\hline 3 & $\mathrm{EU}$ & bond & -0.0003 & 0.0007 & -0.0004 & -0.0035 & 0.0028 & 0.0301 & -0.0635 & 1.0000 & \\
\hline 4 & US & bond & 0.0000 & 0.0003 & 0.0001 & -0.0023 & 0.0014 & 0.5498 & 0.2971 & 0.1864 & 1.0000 \\
\hline
\end{tabular}

to global systematic risks. Similarly, a EU bond investor may want to invest in EU stock than US bonds to reduce her exposure to risks.

$$
a_{t+1}=a\left(1_{t}\right)+\varepsilon_{\mathrm{c}, t+1}
$$

If an investor believes the market is efficient, she will always set alpha to zero. Alternatively, if an investor believes alpha is not zero, it is a function of information variables. We make the conservative assumption that $a\left(I_{t}\right)^{\prime} s$ are linear functions of all information variables. The subset of information variables can produce better estimates and asset allocations. However, if our current estimates of alphas are found to be uscful, it is likely that sophisticated estimates are going to be even more useful. In addition, we assume that investors estimate alphas at each period using the history of data up to the moment. Thus, we updated the regression model at every period. We present the time series of such alphas during the last 500 weeks (1/24/1992-6/24/2005). The results are in Figure 1 and Table 8.

Estimated alphas are very close to zero. It is not surprising because our assets are liquid and traded in efficient market. Given the noise in alphas, we will focus on the sign of alpha to implement any alpha-based strategy, rather than the specific value of it. We conjecture that the estimated sign of alpha is more reliable than the specific value of it. In other words, we conjecture it is more likely that $a$ is positive than negative if the estimated $a$ is positive. For instance, we can express the portfolio weights as functions of $\operatorname{sign}(a)$ such that $w=a$ $+b \operatorname{sign}(a)$. Similarly, we expand asset space to $\left[R_{1} \operatorname{sign}(a) \otimes R_{2}\right]$ from $R_{1}$ using the estimated sign of alpha.

Correlation coefficients also provide interesting insights. Mispricing of assets is positively correlated. Thus, if an asset is under-priced, we may expect under-pricing in the global financial market. One exception is EU stocks and EU bonds. When EU stocks are over-priced, EU bonds are more likely to be under-priced than over-priced. 


\section{Determining Optimal Allocation}

Once we find mispricing, we can implement optimal portfolio in various ways. Suppose an investor optimizes a mean-variance utility. The conditional mean and covariance matrices of a vector of risky asset returns $r$ is as follows:

$$
\begin{aligned}
& \mathrm{E}(r)=\alpha+1 \mu_{r}+\beta \mu_{z} \\
& \mathrm{~V}(r)=\sigma_{r}{ }^{2} 11+\sigma_{z}{ }^{2} \beta \beta^{\prime}+\sum-\mu_{z} \mu_{r} \beta 1^{\prime} .
\end{aligned}
$$

We use notations such as $\mathrm{Er}^{*}=\mu_{\mathrm{r}}, \mathrm{Ez} *=\mu_{\mathrm{z}}, \mathrm{Vr}^{*}=\sigma_{\mathrm{r}}{ }^{2}, \mathrm{Vz}^{*}=\mathrm{O}_{z}{ }^{2}$, Enn ${ }^{*}=$ $\sum$. Given the target return $c$, the optimal portfolio weights on risky assets are

$$
\mathrm{w}=\mathrm{c}(\mathrm{Vr})^{-1} \mathrm{Er} /\left(\mathrm{Er} \cdot(\mathrm{Vr})^{-1} \mathrm{Er}\right) .
$$

If an investor firmly believes the market is efficient, she would use regression model $r_{i, t+1}-r^{*}=\beta_{i, t+1} z^{*}+n_{i, t+1}$ and alphas would become irrelevant. If alpha is included in the estimation, we call it active estimation. Active managers are likely to execute active estimation because they believe they know which are under-priced or over-priced assets.

We can come up with an intuitive and convenient method of asset allocation. To abuse notation, we can regard $r^{*}$ and $z^{*}$ as Hansen and Richard benchmark portfolios. Suppose a is all zero. Then, the two benchmark portfolios $\left\{\mathrm{r}^{*}, \mathrm{z}^{*}\right\}$ fully characterize mean-variance fronticr. Indeed, any return $r$ can be expressed as $\mathrm{r}=\mathrm{r}^{*}+\mathrm{bz}+\mathrm{n}$. Given that $n$ is zero means error term, investors prefer holding a collection $\left\{r^{*}, z^{*}\right\}$ by the amount of $\{1, b\}$ instead of holding $r$. In addition, suppose an investor's target return is $c$. Then, the optimal portfolio of $\left\{\mathrm{r}^{*}, \mathrm{z}^{*}\right\}$ is $\left\{1,\left(\mathrm{c}-\mu_{\mathrm{r}}^{*}\right) / \mu_{2}^{*}\right\}$ to use the orthogonal relationship between $\mathrm{r}^{*}$ and $z^{*}$. This is a version of two funds separation theorem.

If $a$ of any subset of assets are not zero, we have to hold alpha portfolios in addition to the two benchmark portfolios. Any portfolio return $r_{p}$ is decomposed into $r_{p}=a_{p}+r *+b_{p} z^{*}+n_{p}$. Since $a_{p}$ varies with portfolio, an investor should hold $a_{i}+n_{i}$ all $i$ in addition to $r^{*}$ and $z^{*}$ to replicate any portfolio return. Thus, two-fund separation theorem no longer holds. In conclusion, we construct the optimal portfolio for an investor with the two benchmark portfolios and alpha portfolios. More generally, if alpha portfolios exhibit, with any individual asset, correlations that cannot be explained by $\mathrm{r}^{*}$ and $\mathrm{z}^{*}$, then investors hold individual assets with weights that is not spanned by $\mathrm{r}^{*}$ and $\mathrm{z}^{*}$.

It is important to note that the alpha portfolios are multipurpose since fund managers can simply connect them to any other portfolio in accordance with the risk preference of investors and can manage the alpha portfolios independent of other portfolios. For example, we can construct a portfolio that mimics a market portfolio with $r^{*}$ and $z^{*}$. In addition, we can independently create an 
alpha portfolio. If we combine two portfolios, we will get an enhanced index fund. Such strategy of 'attaching alphas' is very closely related with the concept of portability of alpha portfolio which is quite popular in industry (Kung and Pohlman 2004).

We can create alpha portfolios in several ways. Firstly, consider the following portfolio: $r-r^{*}-\beta z *$. Then, it has mean and variance of $a$ and $\Sigma$. Furthermore, the portfolio returns are independent of benchmark portfolios $r^{*}$ and $z^{*}$. To remove portfolios with $a_{i}=0$ and regroup them, we have alpha portfolios. The more groups we have, the more diversification benefits we have, but the harder to manage them. One obvious way of grouping is to exploit Hansen and Richard's model again in the space of alpha portfolios to assemble the equivalences of $\mathrm{r}^{*}$ and $\mathrm{z}^{*}$. One problem with this method is that we should actually hold $\mathrm{r}^{*}$ and $z^{*}$ that contain extreme long/short positions.

Secondly, we can multiply estimated alphas with baseline assets to define augmented asset space (Bansal and Harvey 2004; Brandt and Santa-Clara 2006). We can get the augmented asset space by attaching alpha portfolios to the baseline assets. Let $R_{1}$ be baseline assets, and a's are derived from another asset class $R_{2}$. Then $\left[R_{1} f(a) \otimes R_{2}\right]$ becomes an augmented portfolio, and $f(a) \otimes R_{2}$ is an alpha portfolio. $f(\cdot)$ is arbitrary function of $a$. In particular, we will use the sign function for $f(\cdot)$ in this paper. Conveniently, the alpha portfolio is portable because we can attach this asset into any asset menu. We will focus on this idea since this idea is quite easy to implement. In addition, this paper analyzes the case that the alpha portfolio is appended to the portfolio from which the alpha portfolio is derived: $\left[R_{2} f(a) \otimes R_{2}\right]$. If the alpha portfolio is connected to the other cases in which $R_{1} \neq R_{2}$, it may create more values. The next section estimates parameters of various stochastic processes to implement this idea and to perform out-of-sample test.

\section{PARAMETER ESTIMATION}

To suppress time subscripts, an asset return $r_{i}$ is specified as $r_{i}-r^{*}=a_{i}+\beta_{i} z^{*}+n_{1}$. An investor who believes in an efficient market assumes $a$ is zero and estimates the equation. In contrast, an investor may conjecture that alphas are possibly non-zero when she estimates return processes and tries to seek excess return with the estimated alphas.

We already explained how to estimate alphas, betas and $\Sigma$, the underlying parameters of return processes. We used the specification that $\beta_{t+1}=\beta\left(I_{t}\right)$ and $\mathrm{a}_{\mathrm{t}+1}=\mathrm{a}\left(\mathrm{I}_{\mathrm{r}}\right)+\varepsilon_{\mathrm{a}, \mathrm{r}+1}$. However, the underlying parameters for $\mathrm{r}^{*}$ and $\mathrm{z}^{*}$ should be estimated also to construct conditional mean and conditional covariance matrices of portfolio $\mathrm{V}(\mathrm{r})=\sigma_{t}{ }^{2} 11^{\prime}+\sigma_{z}{ }^{2} \beta \beta^{\prime}+\Sigma-\mu_{2} \mu_{\mathrm{r}} \beta 1^{\prime}$. In particular, we have to make sure that such conditional covariance matrices are always positive definite, 
which has been a very difficult problem in the literature (Brandt and Santa-Clara 2006). We suggest an innovative idea about how to estimate the matrices and to guarantee positive definiteness. Upon the property of $\mathrm{r}^{*}$ and $\mathrm{z}^{*}$, let us specify the conditional moments of $\mathrm{r}^{*}$ and $\mathrm{z}^{*}$ as follows.

Free parameters: conditional mean and volatility of $r^{*}: \mu_{t}, \sigma_{t}$

Specifications for $z^{*}$ :

- Mean of $z^{*}: \mu_{z}=\operatorname{logit}\left(I_{1} b_{1}\right)$

- Correlation between $\mathrm{r}^{*}$ and $\mathrm{z}^{*}: \rho_{z r}=2 \operatorname{logit}\left(\mathrm{I}_{2} \mathrm{~b}_{2}\right)-1$

\section{Theoretical restrictions:}

- Volatility of $z^{*}: \sigma_{z}=\left(\mu_{z}\left(1-\mu_{z}\right)\right)^{1 / 2}$

- Mean of $\mathrm{r}^{*}: \mu_{\mathrm{r}}=-\sigma_{2} \sigma_{\mathrm{r}} \rho_{2 \mathrm{r}} / \mu_{\mathrm{z}}$

- Covariance between $\mathrm{r}^{*}$ and $\mathrm{z}^{*}: \sigma_{2 \mathrm{r}}=-\mu_{2} \mu_{\mathrm{r}}$

In particular, we can specify $\mu_{2}$ and $\rho_{z t}$ with logit functions of information variables $I_{1}$ and $I_{2}$ to ensure that $\mu_{2}$ is in $(0,1)$ and $\rho_{2}$ in $(-1,1)$. Next, we use the property that $\mathrm{Ez}^{*}=\mathrm{Ez} * \mathrm{z}^{*}$ to define volatility of $\mathrm{z}^{*}, \mathrm{Er}^{*} \mathrm{z}^{*}=0$ to compute mean of $r^{*}$. Covariance between $z^{*}$ and $r^{*}$, therefore, becomes $-\mu_{z} \mu_{r}$. With the above specifications, we can construct a likelihood function with the assumption of conditional joint normality and can identify all parameters very easily. This specification also always ensures positive semi-definiteness of a variance-covariance matrix, the proof of which is quite simple.

In this paper, we will take an approach that is even more convenient. We estimate stochastic processes of $\mathrm{r}_{\mathrm{i}}, \mathrm{r}^{*}$ and $\mathrm{z}^{*}$ separately. Then, we check whether $\mu_{2} \mu_{t} /\left(\sigma_{2} \sigma_{t}\right)=-\rho_{z t}$ is always in $\left[\begin{array}{ll}-1 & 1\end{array}\right]$. This always holds indeed, because $\mu_{\mathrm{r}}$ is very small. From the next subsection, we will explain how to estimate the process of $\mathrm{r}^{*}$ and $\mathrm{z}^{*}$.

\section{1. $r *$ process}

By definition, $r^{*}$ is minimum second moment return. It in turn implies that there is very small variation in the time series of $r^{*}$. Let us consider the variance of $r^{*}: \mathrm{V}\left(\mathrm{r}^{*}\right)=\mathrm{Er} \mathrm{r}^{*}-\mathrm{E}\left(\mathrm{r}^{*}\right)^{2}$. Since $\mathrm{Er} \mathrm{r}^{*}$ is minimum by the definition of $\mathrm{r}^{*}$, $\mathrm{V}\left(\mathrm{r}^{*}\right)$ should be even smaller. Indeed $\mathrm{Er}^{*} \mathrm{r}^{*}$ is very close to zero (4.9652e-007). Thus, it is implausible that the conditioning information explains the variation of $\mathrm{r}^{*}$ much. We did OLS regression to check whether the mean of $\mathrm{r}^{*}$ is a function of conditioning information, but the largest estimated coefficient is just $-0.1338 \mathrm{e}-003$, and no coefficient is significant except constant. In addition, we intuitively believe there should be negative or zero serial correlation in mean to reduce the second moments. Moreover, because $\mathrm{r}^{*}$ is minimum second moment return, the process of its volatility should be special. In other words, the impact of large squared 
TABle 9 Stochastic Process of R*

\begin{tabular}{|c|c|c|c|}
\hline Parameter & Value & Standard Error & T Statistic \\
\hline c & 0.0010879 & $1.4052 \mathrm{e}-005$ & 77.4184 \\
\hline $\mathrm{AR}(1)$ & -0.64885 & $9.9413 e-009$ & $-65268044-8485$ \\
\hline$M A(1)$ & 0.50355 & $5.412 \mathrm{e}-010$ & $930441999-4946$ \\
\hline K & $8.7144 \mathrm{e}-009$ & $4.9712 \mathrm{e}-010$ & 17.5299 \\
\hline GARCH(1) & 0.76488 & $2.538 \mathrm{e}-011$ & 30136748127.6526 \\
\hline $\mathrm{ARCH}(1)$ & 0.073207 & $1.7486 \mathrm{e}-010$ & 418658115.6250 \\
\hline
\end{tabular}

Log Likelihood Value: 3890.488870

NOTES: Weekly frequency, Beginning date: $3 / 9 / 1990$, Ending date: $6 / 24 / 2005, N=570$. Stochastic process $r^{*}$ is estimated with $\operatorname{ARMA}(1,1)-\mathrm{GARCH}(1,1)$ specification. $r^{*}$ is constructed by regressing risk free rate on $z(r i-r f) . z$ is information variables including constant terms. We presume $\mathrm{r}^{*}$ is not predicted by information variables. We checked and confirmed this with OIS regression. It is intuitive because $\mathrm{r}^{*}$ minimizes $\mathrm{Er}^{*} \mathrm{r}^{*}$. Thus, there is little variable to be explained by information variables in the time series of $r^{*}$.

Figure 2. Stochastic Process of R*
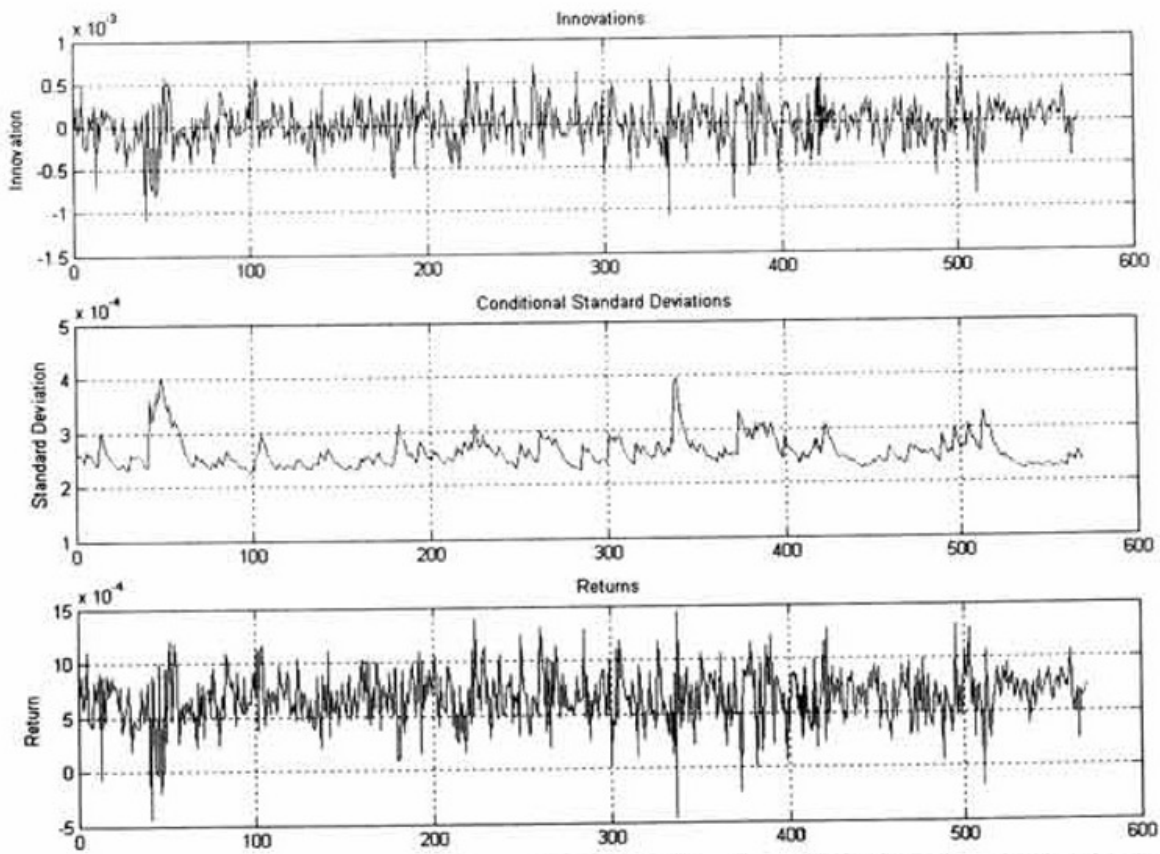

NOTES: Weekly frequency, Beginning date: $3 / 9 / 1990$, Ending date: $6 / 24 / 2005, N=570$. Stochastic process $r^{*}$ is estimated with $\operatorname{ARMA}(1,1)-\mathrm{GARCH}(1,1)$ specification. $r^{*}$ is constructed by regressing risk free rate on $z\left(r_{i}-r\right), z$ is information variables including constant terms. We presume $r^{*}$ is not predicted by information variables. We checked and confirmed this with OLS regression. It is intuitive because $r^{*}$ minimizes $\mathrm{Er}^{*} \mathrm{r}^{*}$. Thus, there is little variable to be explained by information variables in the time series of $r *$. 
Figure 3. Periodicaliy Produced R* and Out of Sample estimates ER* and VR*

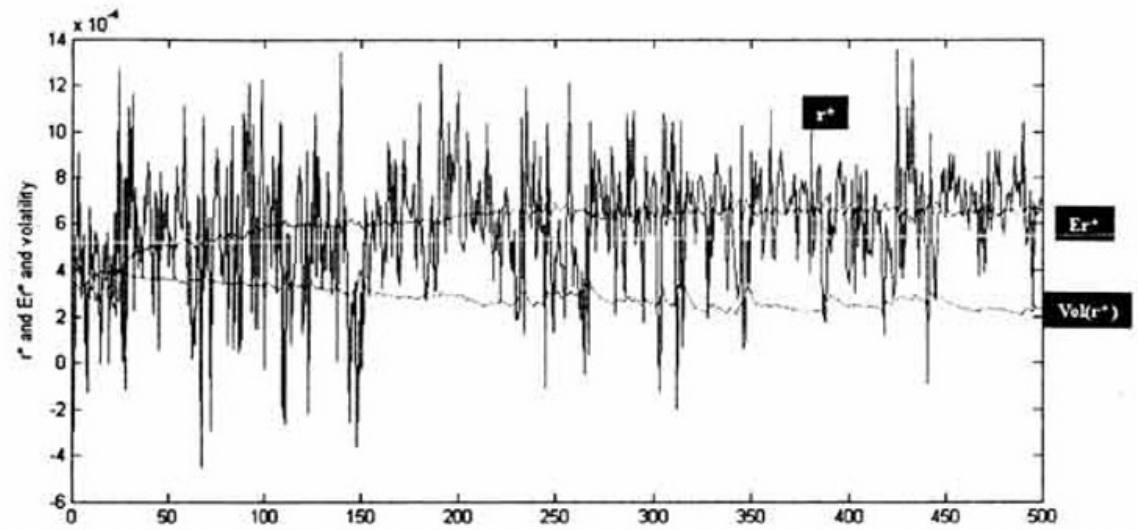

NOTES: $(1 / 24 / 1992 \sim 6 / 24 / 2005)$ We overlay $\mathrm{r}^{*}$ and $\mathrm{Er} \mathrm{r}^{*}$ and conditional standard deviation of $\mathrm{r}^{*}$. $\mathrm{r}^{*}$ is computed by regression risk free rate vector on $z\left(t_{t}-r_{t}\right) . z$ is information variables including constant terms. An investor computes $\mathrm{r}^{*}$ at every period repeatedly. Thus, portfolio weights in augmented asset space change every period for $\mathrm{r}^{*}$. E $\mathrm{r}^{*}$ and conditional standard deviations are estimated every period iteratively with $\operatorname{ARMA}(1,1)-\mathrm{GARCH}(1,1)$.

errors should disappear quickly, and the process of conditional volatility should ensure $\mathrm{E}_{\mathrm{r}} \mathrm{r} \mathrm{r}^{*}$ remains at small values. In sum, $\mathrm{r} *$ should be specified in terms of serial correlation and conditional heteroskedasticity. We checked various specifications, and found that $\operatorname{ARMA}(1,1)-\mathrm{GARCH}(1,1)$ is the most appropriate.

Next, let us consider an investor who computes $r *$ every period. Then, the weights for $r^{*}$ change at every period. We estimate such $r^{*}$ and its volatility using $\operatorname{ARMA}(1,1)-\mathrm{GARCH}(1,1)$. Since we estimate $r *$ every period, the parameters in ARMA(1, 1)-GARCH(1,1) should change in every period too. This affects the dynamics of $r^{*}, \mathrm{Er}^{*}$ and $\operatorname{std}\left(\mathrm{r}^{*}\right)$. We find that $\mathrm{r}^{*}$ is quite predictable, which means that process of pricing operator $\pi(\bullet)$ is fairly predictable too. The estimated Er*and $\operatorname{std}\left(r^{*}\right)$ will be used to construct an optimal mean-variance portfolio. The results are in Table9, Figure 2 and Figure 3.

\section{2. $z^{*}$ process}

To estimate the parameters for the stochastic process $z^{*}$, we use the property that $\mathrm{Ez}^{*}=\mathrm{Ez} * \mathrm{z}^{*}$. To denote $\Phi(\cdot)$ is pdf of standard normal distribution and $\mu(\cdot)$ is logit function to ensure $\mu$ is in $(0,1)$, the likelihood function is

$$
\begin{aligned}
& L=\sum_{t=0}^{I=} \sum_{t=0}^{T-1} \ln \Phi\left(\frac{z_{t+1}^{*}-\mu_{z}\left(I_{t}\right)}{\sqrt{\mu_{*}\left(I_{t}\right)\left(1-\mu_{z}\left(I_{t}\right)\right)}}\right) \\
& \mu_{z}\left(L_{t}=\exp \left(\beta^{\prime} I_{t}\right) /\left(1+\exp \left(\beta^{\prime} I_{t}\right)\right) .\right.
\end{aligned}
$$


Level variables are significant to predict $z^{*}$. Thus, we conclude that the Hansen and Richard benchmark excess return or risk premium $z^{*}$ is predictable. Importantly, it is certain that the predictabilities of $\mathrm{r}^{*}$ and $\mathrm{z}^{*}$ will significantly help portfolio allocation.

Proposition 1: Hansen and Richard benchmark return $r^{*}$ and benchmark excess return $z^{*}$ are very predictable.

Proposition 2: The stochastic process of pricing operator $\pi_{t}(\bullet)$ is predictable.

Next, let us consider an investor who computes $z^{*}$ every period. Then, the weights for $z^{*}$ correspondingly change at every period. We estimated such $z^{*}$ and its volatility using the aforementioned MLE at every period. Hence, parameters in $\mu(\cdot)$ changes at every period also. We checked whether $\mu_{z} \mu_{\mathrm{r}} /\left(\sigma_{2} \sigma_{t}\right)$ was always in $\left[\begin{array}{ll}-1 & 1\end{array}\right]$. Its maximum was 0.95 and its minimum was 0.078 . Thus, the stochastic processes are well defined. In particular, the correlation coefficient becomes stable as we accumulated more data. Our results are in Table 10 , Figure 4 .

Until now, we suggested new methods to estimate conditional moments. Our cconometrics model has several advantages. Firstly, it is known to be very difficult to estimate a conditional covariance matrix as a function of state variables and to ensure positive semi-definiteness at all times. Our method by comparison is very easy to estimate parameters as well as to make certain positive semi-definiteness. Secondly, we know the properties of $\mathrm{r}^{*}$ and $\mathrm{z}^{*}$ which we

Table 10. Stochastic Process of Z*

\begin{tabular}{lcc}
\hline Model 1 & Cofficient & T Values \\
\hline $\mathrm{z}^{*}(\mathrm{t}-1)$ & -0.209700 & -1.277900 \\
constant & -1.370000 & -2.424700 \\
US yield & -0.378600 & -0.104000 \\
US slope & -0.106300 & -0.672700 \\
US lovel & -0.211300 & -1.747900 \\
US spread & 0.241900 & 0.534900 \\
EU yield & 0.826000 & 0.861300 \\
EU slope & -0.008500 & -0.043900 \\
EU level & 0.318300 & 2.587600 \\
\hline
\end{tabular}

NOTES: Weekly frequency, Beginning date: 3/9/1990, Ending date: 6/24/2005, $N=570$. We estimated parameters with MLE. We assume $z^{*}$ exhibits conditional normal distribution with $\mathrm{N}\left(\mu_{t}\right.$, $\left.\mu_{t}\left(1-\mu_{i}\right)\right)$. We use the property that $\mathrm{Ez}^{*}=\mathrm{Ez}^{*} z^{*}$, We specify $\mu, t=\operatorname{Logit}\left(z_{1} \quad \gamma\right)$. The above table shows the parameter estimates for $\gamma$. 
Figure 4. Periodically Produced Z* and out of Sample estimates ZR*

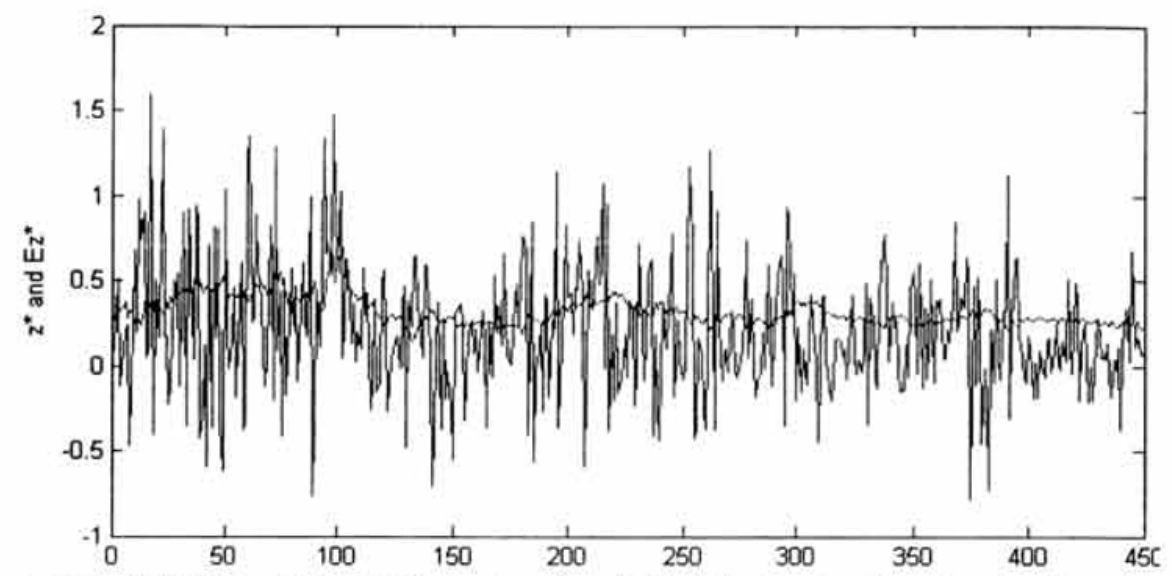

NOTES: $(9 / 30 / 1994 \sim 6 / 24 / 2005)$ We overlay $z^{*}$ and Ez*. Volatile series is for $z^{*}$, and stable series

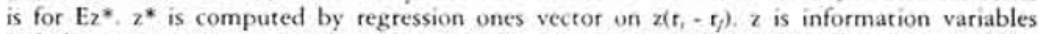
including constant terms. An investor computes $z^{*}$ at every period repeatedly. Thus, portfolio weights in augmented asset space change every period for $z^{*}$. Similarly Ez* is estimated at every period using maximum likelihood estimation (MI.E). It is specified as a logit function of conditional information.

can make use of. Given the property of $\mathrm{r}^{*}$ that it is minimum second moment return, we can estimate its process much easier. We also know the theoretical restriction $\mathrm{Ez}^{*}=\mathrm{Ez}^{*} \mathrm{z}^{*}$ so that we can construct a better MLE for $\mathrm{z}^{*}$. In sum, since we have some prior information about $r^{*}$ and $z^{*}$, we can estimate conditional moments better. Thirdly, we can interpret estimated parameters in ways that are more intuitive because we have some knowledge about Hansen and Richard decomposition and its components.

\section{OUT OF SAMPLE TEST}

Given the estimation method in previous sections, we can perform out-of-sample tests. Our question is whether alpha matters. In particular, we investigate whether 'alpha strategies' are valuable to investors who use conditional information and dynamic allocation, but do not believe alphas are present and view the market as efficient. To rephrase, this section tries to convince investors who are smart enough to use conditioning information, but do not believe that we identified mispricing. Let us consider the four-allocation strategies in Table 11. The time span of this out-of-sample testing is exactly the same to the data period. We rebalanced portfolio conditional information a week ago and assessed its performance at the target week. Thus, our out-of-sample testing is robust. The following subsections are the descriptions for the allocation strategies. 
Table 11. Representative Allocations

\begin{tabular}{l|l|l}
\hline $\begin{array}{r}\text { Active } \\
\text { estimation }\end{array}$ & $\begin{array}{l}\text { Does not consider alphas to estimate } \\
\text { conditional mean and covariance } \\
\text { matrix }\end{array}$ & $\begin{array}{l}\text { Use estimated alphas to compute } \\
\text { conditional mean and covariance } \\
\text { matrix }\end{array}$ \\
\hline $\begin{array}{l}\text { Alpha portfolio not attach } \\
\text { alpha-portfolio }\end{array}$ & $\begin{array}{l}\text { Benchmark (Dynamic) } \\
\text { An investor strongly believes the } \\
\text { market is efficient. Thus, she ignores } \\
\text { any estimation or allocations related } \\
\text { with alpha. She estimates conditional } \\
\text { mean and variance with information } \\
\text { variables. }\end{array}$ & $\begin{array}{l}\text { Active portfolio } \\
\text { An investor believes the market is } \\
\text { inefficient. He actively estimates } \\
\text { alphas and reflects them to compute } \\
\text { conditional mean and covariance. } \\
\text { However, he is not allowed to access } \\
\text { an alpha portfolio. }\end{array}$ \\
\hline $\begin{array}{l}\text { Altach } \\
\text { alpha-portfolio }\end{array}$ & $\begin{array}{l}\text { Augmented portfolio } \\
\text { An investor believes the market is } \\
\text { efficient or does not have ability to } \\
\text { create alpha. Yet she is willing to } \\
\text { attach an alpha-portfolio. She esti- } \\
\text { mates conditional mean and variance } \\
\text { with information variables. }\end{array}$ & $\begin{array}{l}\text { Augmented/Active portfolio } \\
\text { An investor believes the market is } \\
\text { inefficient. He actively estimates } \\
\text { alphas and reflects them to compute } \\
\text { conditional mean and covariance. He } \\
\text { can also access alpha-portfolio. }\end{array}$ \\
\hline
\end{tabular}

\section{Benchmark (Dynamic)}

In this case, an investor estimates conditional mean and variance using predictive variables with the specification that $r_{i}-r^{*}=\beta_{i} z^{*}+n_{i}$. It is important to notice that the investor does not consider alpha. Suppose an investor has 300 weeks of history data. She performs predictive regressions to estimate the relation between future return distributions and conditioning information. Then, given the information available at the current period, she estimates conditional mean and variance. In particular, she estimates the means and covariance matrices with our econometric specification. Next, she implements optimal mean-variance allocation. At the next period, she will have 301 weeks of history data. She performs predictive regressions again to update the relation between future return distributions and conditioning information. Then, she estimates the conditional values with current information. Finally, she implements mean-variance allocation again. In sum, the assets returns and their conditional mean and covariance matrices are specified as

$$
\begin{aligned}
& \mathrm{r}=\mathrm{r}^{*}+\beta \mathrm{z}^{*}+\mathrm{n} \\
& \mathrm{E}(\mathrm{r})=1 \mu_{\mathrm{r}}+\beta \mu_{\mathrm{z}} \\
& \mathrm{V}(\mathrm{r})=\sigma_{\mathrm{r}}{ }^{2} 11^{\prime}+\sigma_{\mathrm{z}}{ }^{2} \beta \beta^{\prime}+\sum-\mu_{\mathrm{z}} \mu_{\mathrm{r}} \beta 1^{\prime} .
\end{aligned}
$$




\section{Augmented Portfolio}

In this case, an investor estimates conditional mean and variance using predictive variables with the specification that $r_{1}-r^{*}=\beta_{1} z^{*}+n_{1}$ which is the same specification to the Benchmark. However, she is willing to admit that other managers have the ability to identify alphas. In particular, she tries the alphas estimated by a researcher who has found the alphas with $r_{i}-r *=a_{i}+\beta_{i} z+n_{i}$ specification. She imports such alphas by constructing augmented asset space $[r \operatorname{sign}(a) \otimes r]$. She iterates this process at every period with the history up to the moment she makes asset allocation decisions. We can model the augmented portfolio as follows.

$$
\begin{aligned}
& {[\mathrm{r} \operatorname{sign}(a) \otimes r]=\left[\mathrm{r}^{*}+\beta z^{*}+\mathrm{n} \operatorname{sign}(a) \otimes\left(\mathrm{r}^{*}+\beta z^{*}+\mathrm{n}\right)\right]} \\
& \mathrm{E}(\mathrm{r})=\left[1 \mu_{\mathrm{r}}+\beta \mu_{2} \operatorname{sign}(a) \otimes\left(1 \mu_{\mathrm{r}}+\beta \mu_{2}\right)\right] \\
& \mathrm{V}(\mathrm{r}) \text { is defined correspondingly }
\end{aligned}
$$

\section{Active Portfolio}

An investor estimates conditional mean and variance using predictive variables with the specification $r_{i}-r^{*}=a_{4}+\beta_{1} z^{*}+n_{i}$. She believes the market is inefficient. She uses our econometrics specification at every period to update the predictability regression model. Conditional means and covariance matrices therefore include information about alpha. We additionally assume that she does not construct alpha portfolio to attach it to the baseline assets. An investor models the Active portfolio as follows.

$$
\begin{aligned}
& r=a+r^{*}+\beta z^{*}+n \\
& E(r)=a+1 \mu_{r}+\beta \mu_{z} \\
& V(r)=\sigma_{t}^{2} 11^{\prime}+\sigma_{z}^{2} \beta \beta^{\prime}+\Sigma-\mu_{z} \mu_{t} \beta 1^{\prime}
\end{aligned}
$$

\section{Augmented/Active Portfolio}

This case combines Active and Augmented portfolio. Therefore, an investor estimates parameters with the specification $r_{i}-r^{*}=a_{i}+\beta_{i} z^{*}+n_{i}$. In addition, she imports her estimated alphas by constructing augmented asset space [r $\operatorname{sign}(a) \otimes$ r]. She iterates this process at every period with the history up to the moment she makes asset allocation decisions. An investor models the Augmented/Active portfolio as follows.

$$
\begin{aligned}
& {[r \operatorname{sign}(a) \otimes r]=\left[a+r^{*}+\beta z^{*}+n \operatorname{sign}(\alpha) \otimes\left(a+r^{*}+\beta z^{*}+n\right)\right]} \\
& E(r)=\left[a+1 \mu_{r}+\beta \mu_{z} \operatorname{sign}(a) \otimes\left(a+1 \mu_{r}+\beta \mu_{z}\right)\right] \\
& V(r) \text { is defined correspondingly }
\end{aligned}
$$


We can compare between Benchmark and Augmented portfolio or between Active and Augmented/Active portfolio to investigate the role of the alpha portfolio. Thus, we can know whether it is a valuable strategy to attach an alpha portfolio. Similarly, we can compare between Benchmark and Active or between Augmented and Augmented/Active portfolios in order to investigate the impact of alphas in conditional means and conditional covariance matrices. We will do such comparisons with out-of-sample tests. Suppose we invest one dollar in Benchmark, Augmented, Active and Augmented/Active portfolios, respectively. We then have the pattern of asset values as Figure $S$ and Table 12.

\section{Figure 5. Asset Values Generated by Representative Portfolios}

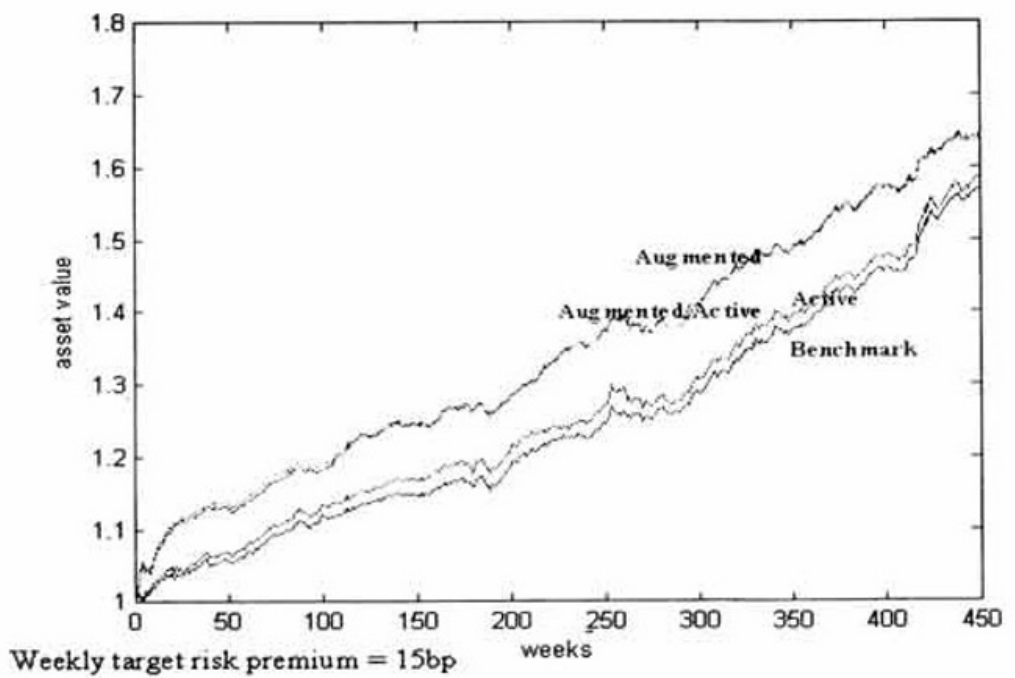

NOTES: $(9 / 30 / 1994 \sim 6 / 24 / 2005)$ This figure displays times series of asset values generated by Benchmark, Augmented, Active and Augmented/Active portfolios. The time series are hypothetical asset values when an investor invests one dollar in each allocation. Out-of-sample test produces the values.

Table 12. Summary Statistics of Representative Portfolio Returns

\begin{tabular}{ccccc}
\hline & benchmark & Augmented & active & augmented/active \\
\hline annualizedmean & 0.0540587 & 0.0599387 & 0.0553333 & 0.0595578 \\
weekly volatility & 0.0029540 & 0.0033125 & 0.0032652 & 0.0032512 \\
annualized median & 0.0600381 & 0.0624535 & 0.0646304 & 0.0630181 \\
annualized max & 1.3213583 & 2.1806943 & 1.4707088 & 2.6227672 \\
annualized min & -0.3702316 & -0.4466280 & -0.5098568 & -0.4281505 \\
sharp ratio & 0.0846040 & 0.1076800 & 0.0836450 & 0.1076000 \\
\hline
\end{tabular}

NOTES: (9/30/1994-6/24/2005). This figure displays summary statistics of asset returns generated by Benchmark, Augmented, Active and Augmented/Active portfolios. We performed out-of-sample test to produce the numbers. 
It seems that the performances of Active and Benchmark are similar. The performances of Augmented and Augmented/Active allocations are very similar too. However, there is a difference when attaching an alpha portfolio to compare Active with Augmented Active or Benchmark with Augmented portfolios. Interestingly, all four portfolios including Benchmark outperform baseline assets such as US, UK, French and Germany stocks/bonds. Our portfolios provide annualized returns similar to those of stocks, but their weekly volatilities are only $1 / 10$ of them. It means that our Benchmark enforces a very high standard, but alpha strategies overcome the bar. Thus, we can conclude that it is a valuable strategy to attach an alpha portfolio. We can increase the sharp ratio by $2 \%$ points with the alpha portfolio. To illustrate, the sharp ratio of the Augmented portfolio is 0.108 , but that of the Benchmark is just 0.08 . Similarly, the sharp ratio of the Augmented/Active portfolio is 0.108 , but that of the Active is just 0.08 . However, the active strategy does not make any difference. The summary statistics are very similar between Benchmark and Active and between Augmented and Augmented/Alpha.

\section{Proposition 3: It enbances the performance of portfolios to import alpha portfolio in order to construct augmented asset space. This result holds whether we estimate underlying parameters with the belief of market efficiency or not.}

Nevertheless, we cannot say for sure that active strategies do not create any additional value. It is possible that our estimates of alpha are too noisy. If we use smarter specifications, Active and Augmented/Active portfolios may beat Benchmark and Augmented portfolios respectively. For example, instead of using all conditioning information variables, we may include only a subset of them to specify alpha: $a_{t+1}=a\left(I_{t}\right)+\varepsilon_{a, t+1}$.

Next, we can check the time series of portfolio weights to know how often they exhibit extreme positions. As Figure 6 shows, we cannot observe any noticeable differences in portfolio weights whether we attach an alpha portfolio or whether we use active estimates. The patterns of each portfolio weight are qualitatively similar. The summary statistics confirm that portfolio weights are not so extreme. Additionally, we find that EU stocks and US bonds exhibit substitutes in all allocations. If EU stocks receive more portfolio weights, US bonds tend to receive more weight too. On the other hand, complementarities exist between US and EU stocks, US stocks and EU bonds, EU stocks and EU bonds, EU bonds and US bonds. US stocks and EU bonds have been complementarities in Augmented strategies, but substitutes in active estimation strategies.

Let us compare Benchmark with Augmented portfolios because it purely shows the impact of alpha portfolios. We can check efficient frontiers of both allocations. As Figure7 shows, the Augmented portfolio dominates the Benchmark portfolio. 
Figure 6. Time Series for Portfolio Weights

Benchmark

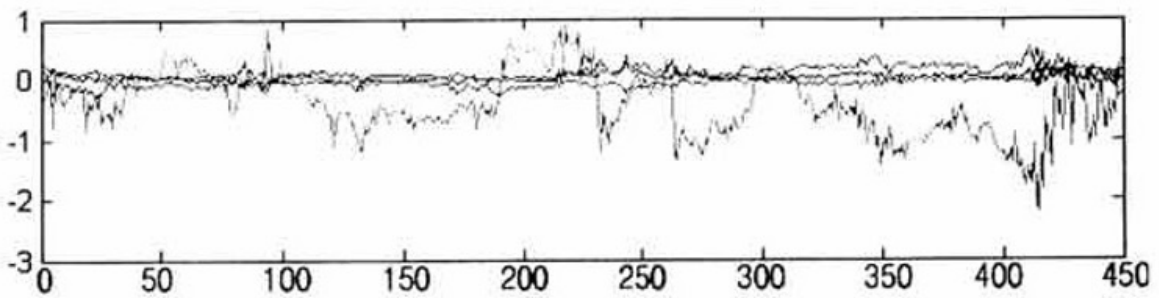

Augmented

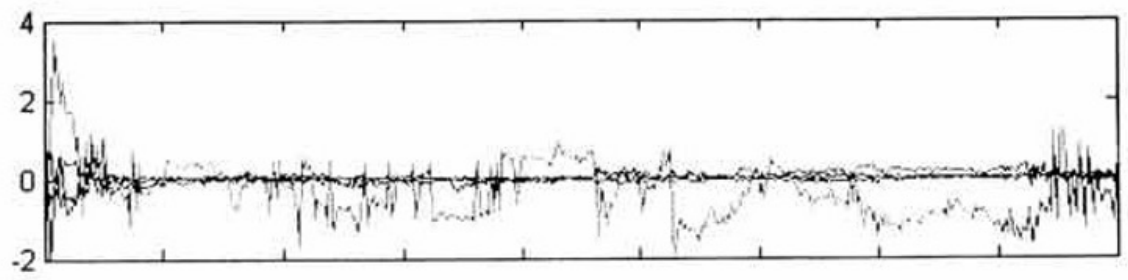

Active

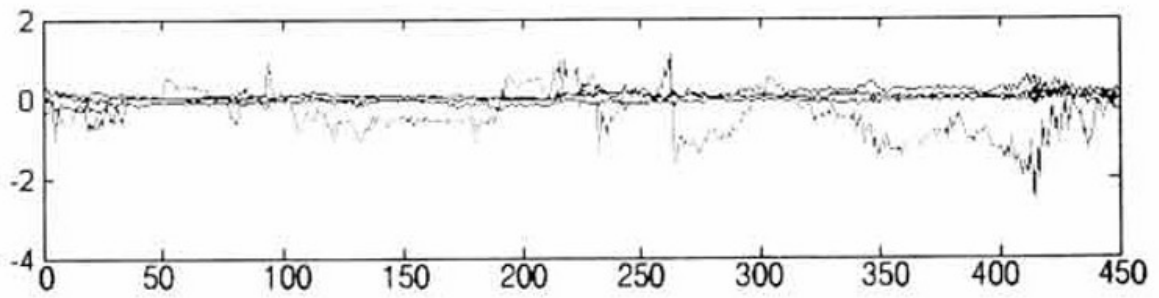

Augmented/Active

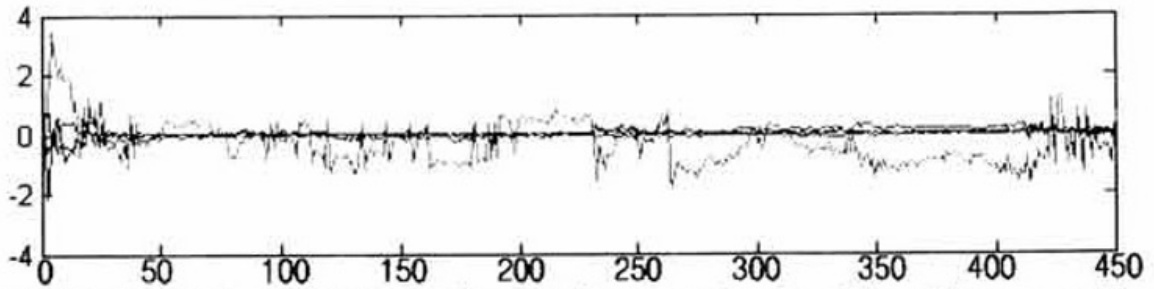

NOTES: (9/30/1994 6/24/2005) This figure displays time series of portfolio weights generated by Benchmark, Augmented, Active and Augmented/Active portfolios. Allocation to US bond is volatile. Allocations to other assets are similar to each other and do not vary much.

Thus, it is natural that our out-of-sample test reveals superiority of the alpha strategy. We can similarly check the efficient frontiers of Active and Augmented/Active allocations. Then we reach exactly the same conclusion. 
Figure 7. Basic Information about Dynamic-Alpha Allocation Under Short SELLING CONSTRAints

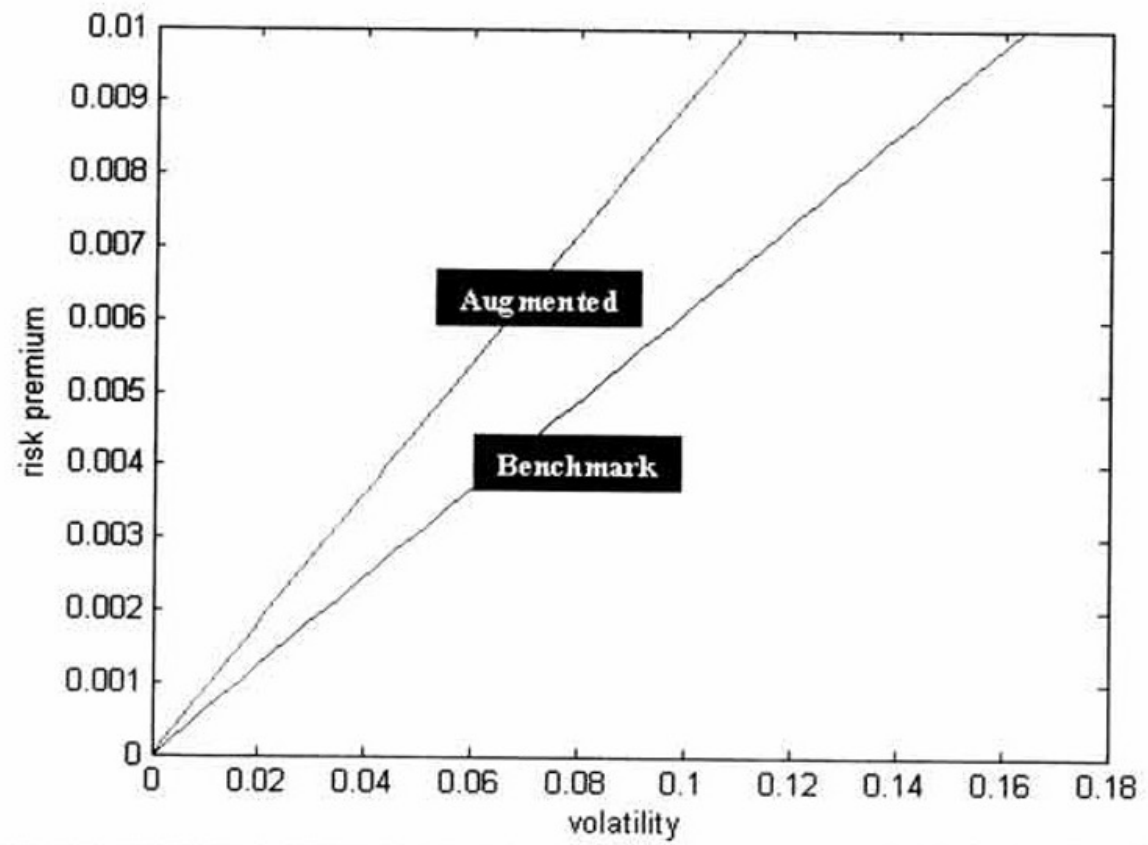

NOTES: (9/30/1994 6/24/2005) This figure displays efficient frontiers related with Benchmark and Augmented portfolios.

\section{Implication of the Design Organization Structure of Fund Families}

Our strategy to attach alpha-portfolio has implications to organizational design issues of fund families. It overcomes the tradeoff between information sharing and moral hazard to manage alpha portfolios independent of managers. Suppose two fund managers are present. If they are encouraged to work together to combine the information they own, they have an incentive to free ride on the effort of the other. On the other hand, if they should compete against each other, their information is not shared, and as a result, the fund family just becomes a collection of various funds without creating any additional benefit. Given the fixed cost to maintain the organization structure, such fund family structure is suboptimal.

Our alpha portfolio provides a solution. Fund managers can make their own independent research to create alphas. Given the records of accomplishment of the relation between those alphas and realized returns, the fund family can optimally design the alpha portfolio and attach them to other portfolios. Conditional 
information and correlations between alpha portfolios and baseline assets determine the manner to optimally integrate information from various sources. To use an analogy, this practice creates a market to trade the skills of portfolio managers.

In relation, the fund family can serve clients better with an alpha portfolio. For instance, suppose a client of a fund family wants to invest in a bond portfolio, but the fund family has a skilled manager in stock division. Then, the fund family can separate alpha portfolios and attach them to a bond portfolio to construct an enhanced bond portfolio. The fund family can control the exposure to the alpha portfolio with mean-variance analysis in consideration of the clients' preference.

\section{CONCLUSION AND NEXT STEP}

W'e offer a dynamic asset allocation method that fills a niche in the existing literature. The method implies a portfolio that identifies market inefficiencies and rebalances itself automatically subject to conditional information. The allocation dominates dynamic strategies that do not account for possible mispricing as well as static strategies in out-of-sample testing. In particular, if we attach an alpha portfolio to existing portfolios, then they perform better in terms of mean and risk. Thus, it makes our alpha portfolio portable such that we can apply it to any portfolio in order to improve its performance. In addition, it is very easy to implement our model. We also suggest an intuitive and convenient econometric model to derive a conditional mean and covariance matrix as functions of predictive variables and to ensure positive definiteness. We additively find that the stochastic process of the pricing kernel is quite predictable. Our framework also has important implications to the organizational structure of fund families because fund families can employ our strategies of porting alpha strategies.

This paper suggests areas of promising future research. We can improve the model upon other refined time-varying volatility models with new conditional information variables. We can use extra sophisticated methods to estimate alpha or to identify mispricing too. This will articulate our dynamic alpha strategies in order to expand the investment opportunity set further. The performance gap between Benchmark and Augmented allocations and between Benchmark and Active portfolios will enlarge further accordingly, so that it will strengthen the conclusion of this paper. In addition, although we suggest an intuitive way to compute conditional covariance matrix as a function of predictive variables, we can elaborate this method further.

We can investigate the impact of short-selling constraints too. In reality, it may not be possible to bet negatively on risky assets. Indeed, fund managers are restricted from to doing short-selling because the cost of short selling is too expensive, regulation prohibits it (e.g. mutual fund), clients can withdraw money 
suddenly, or fund managers are frequently evaluated against index portfolios in which short-selling is absent. Thus, it is important to check whether alpha strategies are still valuable in case short-selling is limited. We find that we reach the same conclusion with short-selling constraints imposed, which could not be included due to the limits placed upon the paper. We will provide the analysis upon request.

Our model has potentials for practical applications too. We present a framework to combine tactical asset allocation and stock selection. In addition, we use only five asset classes such as US stocks/bonds and Euro stocks/bonds and risk free assets. To include more assets would make our model perform better. Thus, it would offer investors with wider investment opportunities. We can also use the model for performance evaluation to check whether any fund manager has created excess return (alpha). Similarly, our model could be a good instrument for a fund of a fund manager to select funds optimally. This model will be also useful to develop an enhanced index fund or even an ETF (Exchange-Traded Funds) because it minimizes the subjective opinion of fund managers, but can create alpha by selecting mis-priced assets. Finally, our portable alpha strategy and econometric model can be useful to traders and risk managers who need to analyze a large amount of trading data on real time basis because our model is simple, quick and economical in terms of computing power. It takes only two seconds to obtain all results with Matlab on desktop personal computers.

\section{REFERENCES}

Ang, Andrew and Geert Bakaert. 2007. Stock return predictability: Is it there? Review of Financial Studies 20(3): 651-707.

Bansal, Ravi, Magnus Dahlquist, and Campbell R. Harvey. 2004. Dynamic Trading Strategies and Portfolio Choice. Working Paper. Duke University.

Bansal, Ravi, and Campbell R. Harvey. 1996. Performance Evaluation in The Presence of Dynamic Trading Strategies. Working Paper. Duke University. Brandt, Michael W., and Pedro Santa-Clara. 2006. Dynamic Portfolio Selection by Augmenting the Asset Space. Journal of Finance 61(5): 2187-2217.

Ferson, Wayne E., and Campbell R. Harvey. 1991. The Variation of Economic Risk Premiums. Journal of Political Economy 99(2): 285-315.

Hansen, Lars Peter, and Scott F. Richard. 1987. The Role of Conditioning Information in Deducing Testable Restrictions Implied by Dynamic Asset Pricing Models. Econometrica 55(3): 587-613.

Kung, Edward, and Larry Pohlman. 2004. Portable Alpha. Journal of Portfolio Management Spring: 78-87.

Shanken, Jay. 1990. Intertemporal Asset Pricing: An Empirical Investigation. Journal of Econometrics 45(1): 99-120. 


\section{ENDNOTES}

1 This work was supported by National Research Foundation of Korea Grant funded by the Korean Government (KRF-2009-332-B00198). 